\title{
Risk factors of the Volgograd labor market of university graduates
}

\author{
Inna Viktorovna Vasilenko $^{1}$, Ekaterina Olegovna Belikova ${ }^{1^{*}}$, and Erkaiym Kozuyeva \\ Sharipova ${ }^{2}$ \\ ${ }^{1}$ Volgograd State University, Institute of History, International Relations and Social Technologies, \\ Department of Sociology and Social Technologies, Volgograd, Russia \\ ${ }^{2}$ Osh State University, Department of Public and Municipal Administration, Osh, Kyrgyzstan
}

\begin{abstract}
This article deals with the problem of risk accumulation in the regional labor market of university graduates as a specific socio-demographic group. Risks are investigated on the basis of a synthetic concept that takes into account the mutual influence of subjective (personal) and objective (contextual) factors. The article aimed to study the risk factors of subjective and objective nature in the regional labor market of university graduates. The analysis of the available scientific experience has shown that there is no holistic concept of risks in the labor market of graduates, although there are works that study professional risks in the context of employment, analyzing the situation of young people in the labor market. Risk factors were investigated based on four characteristics describing the risk society: the uncertainty of the situation, uncertainty of the environment, unpredictability of the development trend, and inadequacy of personal resources. The inadequacy of resources is the level of theoretical and practical preparedness, the correspondence of the performed functions to the received specialty, and the desire to change jobs. The information was collected using an online questionnaire. The analysis of each characteristic of the regional labor market showed the presence of enlarged risk factors influencing the decision to choose a job: lack of information and knowledge about the situation in the labor market and insufficient professional potential of graduates, who are motivated only by a prestigious, well-paid job, rather than by creativity and self-realization in their profession.
\end{abstract}

Keywords: risky nature, synthetic concept of risk, risky situation, labor market, difficulty of orientation, unpredictability of resources

\section{Introduction}

\section{$1.1 \quad$ A Subsection Sample}

The famous Russian sociologist Yanitsky claimed that Russia was a risk society [1]. Risks are created, spread, overlap, permeate the whole social system, are included in social life,

\footnotetext{
* Corresponding author: eo belikova@volsu.ru
} 
creating conditions for new risks. Risks interfere with the normal functioning of all subsystems and institutions; the control over them is gradually being lost. The labor market is no exception: risks emerge and constantly multiply here as well. The market system is the basis of economic and social development, so the risky nature of its functioning negatively affects all social actors, from the micro level - individuals, their families, organizations, ending with the macro level - institutions, including the state. This situation does not contribute to the development of the state and society but inhibits their positive dynamics. This article will focus not only on the risks in the labor market but also on the dangers in the labor market for graduates of higher education institutions, which are created both by objective conditions and by the young subjects of the market themselves. It should be noted that the nature of risks in this labor market is conditioned by the peculiarities of these subjects. For example, the risks in the labor market for graduates of the humanities will be different from those for graduates of technical specialties. Risks for young subjects who have not graduated from a higher education institution will be different from those for former students.

\subsection{Analysis of the theoretical groundwork for the study of risks in the labor market of graduates and young people}

To begin the analysis of the scientific literature on this or similar topics, one can consider the keywords present in this topic. Talking about the risks in the labor market of university graduates, it should be noted that this combination of key concepts is rarely found in publication titles. The research by Yekaterinburg sociologists is devoted to identifying the risks and threats that arise for young people in the modern regional labor market [2], such as unemployment [3].

The greatest threat in the regional labor market is the mismatch between places of employment and the qualifications and skills obtained. This not only leads to the loss of professional skills and competencies but also increases the probability of other risks in the labor market. There is scientific literature devoted to occupational risks, which in a certain way relates to this study as well [4-8]. Three main approaches to the study of risks were considered above: objective, subjective, and synthetic. The authors listed above are supporters of either the first or the second approach. Some authors consider the contradiction between the desire of young people for self-development and the dysfunctions of contemporary Russian society [5,8]. At the same time, other authors pay more attention to the role of young people's professional behavior, professional choices that lead to risks $[4,6,7]$.

The main part of scientific research is devoted directly to the issue of employment, without conceptualizing risks and their universality in Russian society [9, 10]. A number of works do not consider risks, but investigate the issues of the socially safe youth labor market and the impact of casual employment on it [9]. Some scientists consider the situation in the labor market as a crisis, due to the persistence of social stereotypes and non-compliance of the profession with the requirements of the labor market [10]. In the authors' opinion, these views refer to the production of risks in the labor market, but the labor market is not considered as part of the risk society, there is no analysis of the content side of the risks. 


\subsection{Research methodology}

It is known that there are two consolidated approaches to the study of risks: objective and subjective. According to the first one, risks are presented as objectively existing dangers, threatening the loss of something valuable for a person and society. "Hazards are treated as independent variables, and people's reactions to them are treated as a dependent one" [11]. The second approach emphasizes the subjective side of risks, that is, their perception. Therefore, on the basis of this approach, the risk does not exist if one is not aware of it. Risks are constantly produced by society because they are consequences of social actions such as decision-making $[12,13]$. In the authors' opinion, it is not possible to limit the study of risks to one side of reality, but it is necessary to consider both of them, especially since in everyday life, subjects' perception of the situation depends directly on the context, that is, the established everyday reality, which is perceived by subjects in different ways. It is not by chance that Giddens pointed out the existence of an ever-increasing dependence between everyday decisions of individuals and the transformation of structural elements of society, the consequence of which is the risks [14].

There is a very good classification of characteristics of this context of risk: unrecognizability, uncertainty, unpredictability, and inadequacy of personal resources [1]. These features allow describing the basic conditions of risk society functioning, in this case, it is the graduate labor market.

\section{$2 \quad$ Materials and methods}

The labor market includes not only those who look for work and provide vacancies but also those who work, but in the current conditions of instability and uncertainty of the labor market situation can lose their jobs. The article aims to describe the risk characteristics of the regional labor market of Russian regional university graduates and to fill them with the real empirical content of social facts.

Unrecognizability occurs when the usual course of life is disrupted, when stereotypes and social dispositions break down, and when individuals do not have the necessary information about the situation. In relation to work, this characteristic can be given meaning through graduates' attitudes toward their permanent (formal) employment, the identification of the ways and agents, by which job search was carried out, and the presence of professional continuity in the family [15].

Uncertainty is the most important property of the modern era. The risk in this situation is the result, including in the labor market [16]. Uncertainty as a basic feature of the risk society, as a context surrounding a graduate in the labor market, will be defined by the indicator - the main difficulties in finding a job.

Unpredictability occurs because most people may not be aware of most of the risks in most cases [17]. The unpredictability of the situation in the labor market for graduates in general and specifically for this individual was clarified by such indicators as the content of future plans and the characteristics of future work.

The inadequacy of resources makes it possible to define the presence of risks through the potentials of protection of the subject [18]. The potential is identified through the level of theoretical and practical competence, compliance of the functions performed with the received specialty, and the desire to change/not to change the specialty. 
Based on the above, below is a methodological scheme of the situation of graduates of higher education institutions in the labor market and the risks they face in one of the regions of modern Russia (Volgograd and the Volgograd Region) (see Fig. 1):

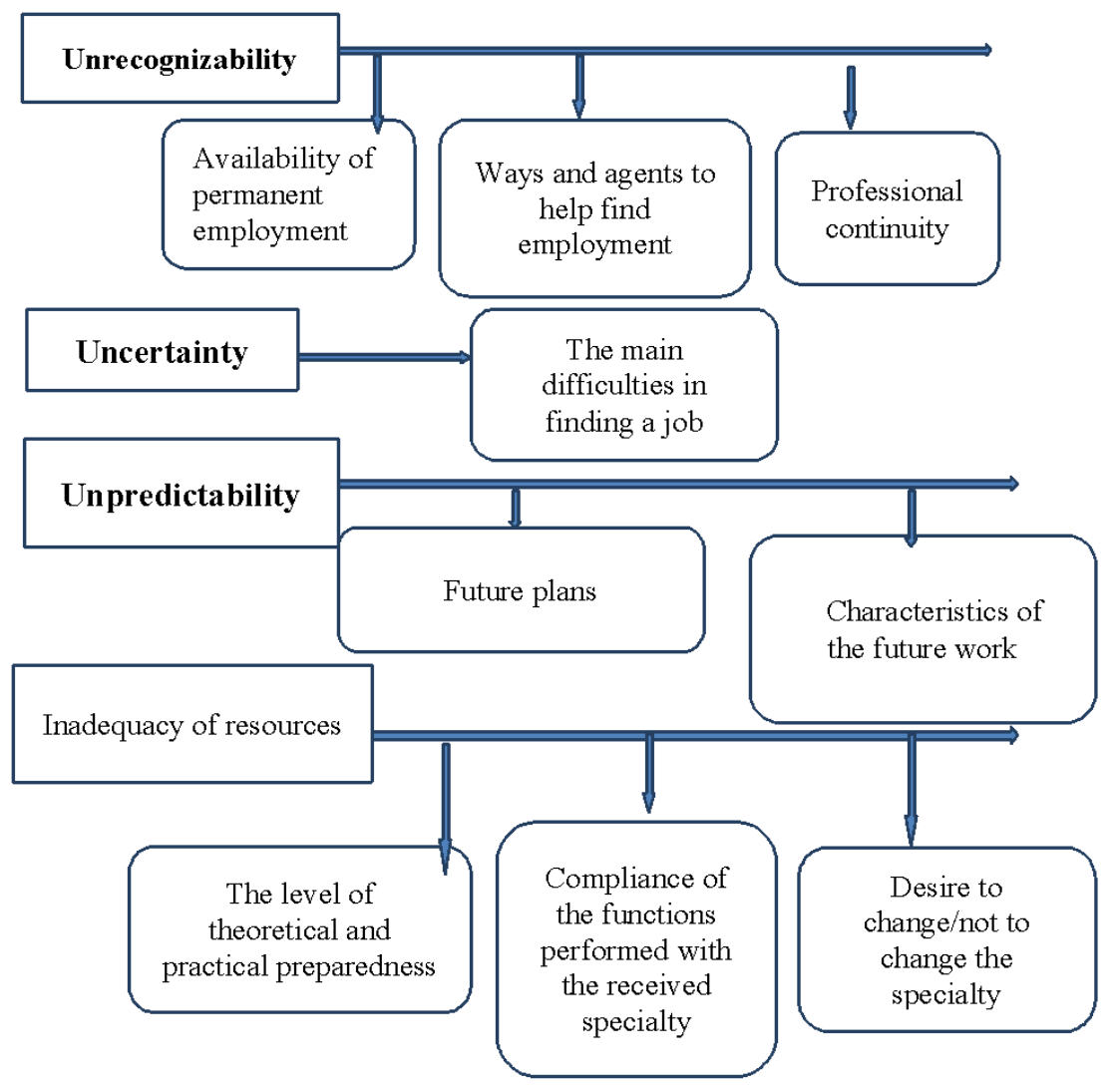

Fig. 1. Methodological model of the study of risk factors in the labor market for graduates of regional universities.

Based on this methodological model, a questionnaire was developed that included three blocks of questions. The purpose of the first block was to get information about the contradictions between the existing stereotypes and the real situation. The questions of the second block were aimed at finding out the uncertainty in the context of graduates' labor market and their awareness of this uncertainty. The third block included questions to investigate the unpredictability of the situation in the labor market and the respondents' knowledge about it. The fourth block of questions made it possible to determine the respondents' real and potential resources for protection in the labor market.

This questionnaire was used to conduct an online survey (the Google platform was used). The sample size was 376 people, and the survey was conducted in September-October 2020. The data obtained were processed using the SPSS Statistics 21 application package.

The objects of the study were residents of the city of Volgograd $(n=200)$ and the Volgograd Region, in particular residents of the Kamyshinsky, Frolovsky, and 
Mikhailovsky Districts ( $n=176$ ). The number of male respondents was $43 \%$ and the number of female respondents was $57 \%$. The age distribution of the respondents was as follows:

respondents aged $21-22$ were $30.0 \%$;

respondents aged $23-24$ were $42 \%$;

respondents aged 25 years and older were $28.0 \%$.

The study involved graduates who had obtained social professions: economists $(21.0 \%)$, lawyers $(16.0 \%)$, managers $(34.0 \%)$, sociologists and social workers $(9.0 \%)$, and psychologists $(20.0 \%)$, which allowed obtaining the opinion of representatives of different categories of former graduates of regional universities about the labor market and risks there.

\section{$3 \quad$ Results}

The first characteristic is unrecognizability. According to the results of the survey, $45.0 \%$ of graduates have permanent (formal) employment, and 55.0\% do not have it. In this case, permanent employment denotes not those characteristics of work that existed before: stability, sustainability, and security, but simply a variant of formal, rather than informal, work. The data indicate that risks exist for both groups of graduates, as some do not have any protection from the actions of employers at all, and others, although they do, perhaps not for long. At this point, no protection from the situation and no change for the better is in sight for this group of graduates.

Unawareness of the situation in the labor market makes former graduates ask their acquaintances $(41.0 \%)$ and relatives $(9.0 \%)$ for help in finding a job. The other half got a job by sending out CVs $-26.0 \%$ or by choosing a job from a list of vacancies $(21.0 \%)$. Three percent stayed on after the training practice. In other words, respondents reduce the level of unrecognizability of the situation at the expense of those who know it better, at least in some part. These are acquaintances, friends, and relatives, these are vacancies provided by employers in mass media and searching for workers with their help. At the same time, the first examined indicator shows that even after employment, the risk of the environment does not decrease.

The next indicator concerns the continuity of the profession received. It is no secret that a significant part of parents try to get their children into the sphere of activity in which they themselves work. The survey showed that the complete continuity of the profession was observed in $12.0 \%$ of the respondents, partial continuity, defined as a specialty close to the one their parents had $-26.0 \%$. The rest had no such connection of professions. In other words, more than $60.0 \%$ did not find out the continuity of the profession. This means that for the majority of the respondents, the unrecognizability of the situation in the labor market is very high, and hence the riskiness as well.

The uncertainty of the situation in the labor market was determined by analyzing the main difficulties in finding a job. The study showed that the main difficulties in finding a job are: the lack of decent places in the labor market (high wages, interesting work, prospects of promotion) $-50.0 \%$ of respondents; lack of assistance of universities in employment $-18.0 \%$, the lack of vacancies in the specialty $-18.0 \%$, and the requirement of practical experience by employers $-16.0 \%$. The uncertainty of the situation in the labor market often leads to inadequate requirements for the professional potential or makes graduates look for agents who can help them become oriented in the labor market - these are universities. The university has a big role to play as an organization that can help graduates enter the labor market according to their specialty and on good terms. Forty-four percent of the graduates counted on universities and considered such assistance necessary, 
$40.0 \%$ were less demanding, but assessed such assistance as rather necessary. Only $8.0 \%$ of respondents said they did not need it, and $8.0 \%$ found it difficult to answer. Thus, the majority of former graduates considered the assistance of the university in employment necessary.

The next feature characterizing the riskiness of the situation in the labor market is unpredictability. It was revealed with the help of the information about who from the nearest environment most influenced the formation of future plans, and about the criteria for evaluating the future place of work. The first aspect of unpredictability arises from the fact that it is impossible to foresee how the situation in the labor market will develop, although the image of a promising job exists in the minds of respondents. The second aspect concerns the personal potential of graduates and its adequate assessment. So, the main features of perspective work, which were highlighted by respondents, are: the reputation and fame of the organization $-64.0 \%$, the stable position of the organization $45.0 \%$, the level of salaries $-37.0 \%$, a favorable atmosphere in the team $-27.0 \%$, the prospective development of the organization $-23.0 \%$, decent social package $-22.0 \%$, the availability of career prospects $-15.0 \%$. Respondents are much less interested in: the duties performed $-12.0 \%$, the possibility of professional development $-12.0 \%$, the convenient location of the office $-8.0 \%$.

Naturally, the respondents named more than one trait at a time, so it is very difficult to predict the situation in which there will be vacancies in organizations of this kind. However, graduates do not research labor markets and do not have accurate information about the development of the situation in it. At the same time, information is drawn from relatives and acquaintances, whose knowledge is also minimal or even non-existent. At this, it is known that the risks are reduced by the available information, but it should be small in volume and rich in content. When asked who influenced the formation of plans for the future, the respondents provided the following answers: $48.0 \%$ made plans for the future on their own, $30.0 \%$ were guided by the opinion of parents and other relatives, $8.0 \%$ took into account the opinion of friends and acquaintances, $8.0 \%$ listened to teachers, and $6.0 \%$ trusted the media. The data obtained indicate that the majority of respondents either make independent decisions about their future or are influenced by their parents, but nowhere in the answers does the employment service or data about the situation in the labor market in the region appear. The lack of accurate information undoubtedly increases the riskiness of the graduate labor market.

The last characteristic of the labor market riskiness is the inadequacy of the respondents' resources. The assessment of the situation in the labor market according to this characteristic was determined by indicators concerning the level of theoretical and practical preparedness (self-assessment), correspondence of the functions performed to the received qualification, and the desire to change the place of work.

The survey showed that $65.3 \%$ of the respondents evaluated their level of theoretical knowledge as average, $23.1 \%$ evaluated it as high, 9.6\% evaluated it as low, and $2.0 \%$ found it difficult to answer. Besides, $46.2 \%$ of the respondents assessed their level of practical training as average, $30.7 \%$ assessed it as low, $19.2 \%$ assessed it as high, and 3.9\% had difficulty answering. The findings suggest that graduates rate their level of professional training as average. In terms of risk, this means that, with average potential, graduates are also moderately protected against the risk of losing their jobs or the risk of performing uninteresting duties.

The next indicator of the inadequacy of resources for the modern labor market is aimed at identifying the correspondence of the functions performed to the received specialty. Only $9.1 \%$ of the graduates believe that their work fully corresponds to the received 
qualification. For $59.1 \%$ of the respondents, the job corresponds partially to the specialty. For more than a third of the respondents, it does not correspond to the specialty at all. Thus, the possibility to use professional potential at the average level of training leaves much to be desired. It means that the potential of protection of graduates of universities from a change of situation, from risks of loss of a job or positive results of its search, is utterly low.

Finally, the last indicator is a subjective assessment of one's resources related to the acquired specialty. This indicator shows that the situation is assessed and the respondent hopes/does not hope that he/she will be able to use his/her resources. The survey shows that $31.8 \%$ of respondents are quite satisfied with their specialty and would not want to change it, $13.6 \%$ of the respondents are less sure about it, but still would not want to change their specialty either. This group makes up $45.4 \%$. Besides, $13.6 \%$ of respondents are sure they would like to change their specialty. Another $13.6 \%$ of respondents, though not so sure, but still would like to change their specialty. Together this group makes up $27.2 \%$, i.e. about a third. Also, 9.1\% found it difficult to answer the question (see Fig. 2). Thus, about one-third of respondents-graduates are aware of the risk of insufficiency of their professional potential in the modern labor market, related to the obtained specialty. However, there is an unconscious risk of inadequate assessment of their resources and additional expenses for getting another specialty.
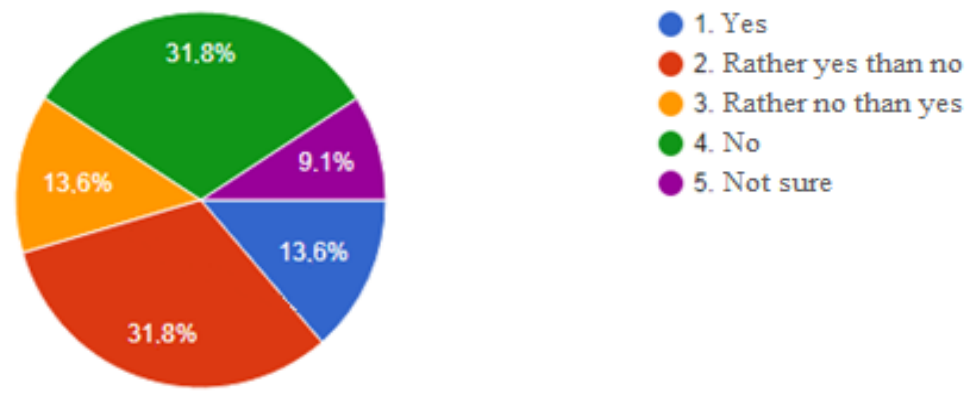

Fig. 2. Respondents' decision to change/not to change their specialty, \%.

An important addition to the subjective assessment of the potential of one's specialty in the labor market is the respondents' disposition with respect to the specialty as the main professional path. There were no respondents with a positive, stable disposition. A positive, but not stable disposition, expressing that working in a specialty should rather be a professional path than not, was characteristic of $58.0 \%$ of the respondents. Six percent of respondents had a negative stable disposition, and $26.0 \%$ of them had negative, but not stable disposition (the specialty should rather not be the main professional path). In the dispersion of dispositions, the problem of resources and adequate estimation of them is traced, which is formed initially, still at the solution of a problem: what university to enter and what specialty it is better to receive and with what purpose.

\section{Discussion}

The most important problem in the context of the universality of risks is the riskiness of the youth labor market in general, and the labor market of graduates of higher education institutions, in particular. This problem is most acute at the regional level. Certain knowledge in this field has been formed in the scientific literature. Scientists studying regional labor markets identify, first of all, the threat of unemployment; non-compliance 
with labor legislation; work not in the specialty and "leaving" the profession, as well as salary risks; involvement in informal employment [9]. A number of authors consider the core of all risks to be professional risk, as a result of the non-compliance of the profession with the requirements of the modern labor market and the lack of necessary jobs $[2,7,10]$. These social facts are a consequence of the spread of risk factors in the labor market: the lack of information among young people about its condition, the low level of theoretical and practical competence of graduates, and the lack of clearly expressed motivation to obtain a specific specialty.

In this study, the riskiness of factors affecting the regional labor market was considered differently.

First, it was done based on the concept of the universality of risk in Russia.

Second, it was done with the help of the following characteristics: unrecognizability, uncertainty, unpredictability, the inadequacy of resources describing a risky situation.

Third, the research was guided by a system of indicators that describe each characteristic of the risk situation in the labor market.

Fourth, the fullness of these characteristics with real social facts of subjective and objective reality was analyzed.

Fifth, it was done identifying on this basis the range of risk factors of the regional labor market.

Of course, some results of this article echo the conclusions of the scientists listed above. For example, the one-sided motivation of graduates only for a prestigious job, without taking into account their own potential, which they themselves estimate as average.

It is necessary to continue further work on the study of risk factors in the regional labor market. It is planned to get information about the market situation from employers, parents, as well as graduates themselves, but also with the help of qualitative methods, if the coronavirus pandemic does not interfere with the collection of information.

\section{Conclusion}

Currently, in the regional market of graduates of higher education institutions who have received quite popular professions, risk factors of a subjective and objective nature are being formed and continue to be produced. Subjective risk factors are created by the results of graduates' decision-making in the conditions of limited information, poor knowledge of the market situation, and low professional potential. Objective factors are manifested in the risky social context surrounding the graduates and embodied in the current conjuncture of the labor market, parents' advice, friends' ideas, information and images transmitted by the media.

The situation in the regional labor market was described based on four characteristics of the risk society: unrecognizability, uncertainty, unpredictability, and inadequate resources.

The unrecognizability of the situation is formed due to the existence of formal and informal employment. According to this indicator, more than half of the respondents do not have formal employment. The risks within this characteristic increase due to the fact that some graduates cannot use acquaintances and personal relations during employment, which means they do not have information about their future work. Half of the respondents are such graduates. The lack of occupational and parental continuity for $60.0 \%$ of graduates also increases the risk of a lack of knowledge of the regional labor market situation for graduates.

The uncertainty of the situation was clarified with the help of an indicator of the presence of difficulties in finding employment. Risks are created in the labor market by the 
overestimated motivation of graduates for a prestigious job, the imbalance between the received specialty and vacancies in the labor market, and the desire to solve their employment problems at the expense of the university.

The unpredictability of the situation is manifested in the idealized image of the future place of work and for half of the respondents in the absence of "guides" in the labor market who can not only clarify the situation but also help with employment.

Finally, the inadequacy of resources is manifested in the average level of theoretical and practical readiness of graduates, indifference to the choice of specialty, employment not in the specialty, when the duties performed do not correspond to the profession received, and as a result, the desire to urgently change one specialty to another without a guarantee of a change in the situation.

\section{Reference}

1. O.N. Yanitsky, Sotsiologiya riska [Sociology of risk]. (LVS Publ, Moscow, 2003)

2. A.N. Tarasova, A.N. Chernyh, Bul Tyumen State Univ. Soc-Econ Leg Stud, 5(4(20)), 52-75 (2019)

3. M. Choudhry, E. Marelli, M. Signorelli, Int J Manpower, 33(1), 76-95 (2016)

4. E.V. Kombarova, Central Rus Bul Soc Sci, 1, 44-49 (2010)

5. E.V. Zinchenko, Professionalnaya karera talantlivoi molodezhi: perspektivy $i$ vozmozhnye riski [Professional career of talented youth: prospects and possible risks], in A.V. Chernaya (ed), Materials of the All-Russian scientific and practical conference "Personality in culture and education: psychological support, development, socialization", Southern Federal University, 11-13 December, 2018, 6, 51-56. (Foundation, Rostov-on-Don, 2018)

6. A.B. Fokina, News Higher Edu Inst. Soc. Econ. Pol, 4, 88-90 (2014)

7. Yu.M. Pasovets, Innov Expert: Sci Works, 1(26), 166-176 (2019). https://doi.org/10.35264/1996-2274-2019-1-166-176

8. N.Yu. Priyatkina, Mod Prob Sci Edu, 4, 118 (2019)

9. L.F. Gurbaeva, Forum. Ser: Human Econ Sci, 2(17), 192-196 (2019)

10. M.A. Gnatiuk, A.A. Horovinnikov, S.I. Samygin, Sci Notes, 2, 157-163 (2018). https://doi.org/10.22394/2079-1690-2018-1-2-157-163

11. M. Douglas, Risk Acceptability According to the Social Sciences. (Russel Sage Foundation, New York, 1985). https://doi.org/10.4324/9780203708781

12. U. Beck, Risk Society. Toward a New Modernity. (SAGE, London, 1992)

13. U. Beck, Ecological Enlightenment. Essays on the Politics of the Risk Society. (Humanities Press, New Jersey, 1995)

14. A. Giddens, Living in a Post-Traditional Society, in Beck U., Giddens A., Lash S. Reflexive Modernization. Politics, Tradition and Aesthetics in Modern Social Order. (Stanford University Press, Stanford, 1994)

15. R. Sennet, The Corrosion of Character. (Norton, New York, 1998). https://doi.org/https://doi.org/10.5172/jmo.1999.5.2.53

16. Z. Bauman, Liquid Modernity. (Polity Press, 2000) 
17. M. Douglas, A. Wildavsky, Rick and Culture: An Essay on the Selection of Technological and Environmental Dangers. (Univ. of California Press, Berkley and Los Angeles, 1982)

18. R. Reich, The Work of Nations. (Vintage Books, New York, 1991) 